\title{
Capsule Commentary on Walsh et al. Sexual Violence and Mental Health Symptoms Among National Guard and Reserve Soldiers
}

\author{
Michelle D. Sherman, PhD \\ Oklahoma City VA Medical Center and University of Oklahoma Health Sciences Center, Oklahoma City, OK, USA.
}

J Gen Intern Med 29(1):179

DOI: $10.1007 / \mathrm{s} 11606-013-2575-1$

(c) Society of General Internal Medicine 2013

$\mathrm{W}$ alsh et al. ${ }^{1}$ explored the relationship between sexual violence, PTSD, and depression among National Guard and Reserve soldiers, finding $27-37 \%$ of women and $4 \%$ of men reported experiencing sexual violence at some point in their lives. Rates of sexual violence during the most recent deployment ranged from $0-2.6 \%$. Moreover, soldiers who had ever experienced sexual trauma had 3.5-fold higher odds of suffering from PTSD; nearly half of PTSD cases could be attributed to life-time sexual violence. The rate of deployment-related sexual trauma in this population-based cohort is lower than that reported in VA samples.

A major strength of this study is its large randomized sample that is not drawn from the VA or a treatment-seeking population. That lifetime rates of sexual violence are elevated among female soldiers, and that these experiences increase vulnerability to mental health problems, are important findings both for epidemiological purposes and to enhance treatment efforts.

The assessment of sexual violence was done within the context of screening for 21 different traumatic events, and subjects were asked if they have ever "been raped" or "experienced another kind of sexual assault or unwanted sexual contact as a result of force, threat of harm, or manipulation." As the authors note, this use of single questions may underestimate the prevalence of sexual assault. Further, it would be helpful in future studies to differentiate between childhood sexual abuse and such assault in adulthood. The CDC's Adverse Childhood Events studies have documented a high prevalence of childhood sexual abuse $\left(17.2 \%\right.$ for women and $6.7 \%$ for men). ${ }^{2}$ Other research has documented similar or higher rates of childhood sexual abuse, and studies have reported increased risk for individuals with this history for a range of psychiatric and other life difficulties. ${ }^{3,4}$ Future research would benefit from exploring both the timing and context of sexual violence among soldiers, trying to differentiate the contribution of childhood experiences versus sexual trauma that occurred in adulthood but prior to military service.

Walsh and colleagues urge clinicians to assess lifetime sexual violence both in treatment-seeking clients and in all soldiers. While this assessment is likely routine in most psychiatric treatment settings, this research highlights the importance of assessing this domain regularly in primary care settings and in research. Enhancing our ability to conceptualize the many factors that contribute to human suffering is important to improving our assessment and intervention approaches.

Conflict of Interest: The author has no conflicts of interest with any of the material in this manuscript. The views expressed in this article are those of the authors and do not necessarily represent the views of the Department of Veterans Affairs.

Corresponding Author: Michelle D. Sherman, $\mathrm{PhD}$; Oklahoma City VA Medical Center and University of Oklahoma Health Sciences Center, Oklahoma City, OK 73104, USA (e-mail: Michelle.sherman@va.gov).

\section{REFERENCES}

1. Walsh K, Koenen KC, Cohen GH, Ursano R, Gifford RK, Fullerton CS, Galea S. Sexual violence and mental health symptoms among National Guard and Reserve soldiers. J Gen Intern Med. 2013. doi:10.1007/ s11606-013-2555-5.

2. Center for Disease Control and Prevention. Adverse childhood experiences reported by adults - five states, 2009. Morb Mortal Wkly Rep (MMWR). 2010;59(49):1609-13.

3. Dube SR, Anda RF, Whitfield CL, Brown DW, Felitti VJ, Dong M, Giles WH. Long-term consequences of childhood sexual abuse by gender of victim. Am J Prev Med. 2005;28(5):430-8.

4. Nelson EC, Heath AC, Madden PA, Cooper ML, Dinwiddie SH, Bucholz KK, Glowinski A, McLaughlin T, Dunne MP, Strathham DJ, Martin NG. Arch Gen Psychiatry. 2002;59(2):139-45. 